\title{
AVALIAÇÃO DA QUALIDADE DA SEMEADURA DIRETA DO MILHO EM FUNÇÃO DO AUMENTO DA VELOCIDADE DE DESLOCAMENTO E DO ESCALONAMENTO DE MARCHA DE UM CONJUNTO TRATOR-SEMEADORA-ADUBADORA
}

João Cleber Modernel da Silveira ${ }^{1}$, Haroldo Carlos Fernandes², Daniel Mariano Leite ${ }^{3}$, Mauri Martins Teixeira ${ }^{4}$, Marconi Ribeiro Furtado Júnior ${ }^{5}$

\section{RESUMO}

Objetivou-se, com a realização neste trabalho, avaliar a qualidade da semeadura de um conjunto trator-semeadoraadubadora em sistema de plantio direto, em função de diferentes velocidades de deslocamentos e de rotações no eixo do motor, na semeadura da cultura do milho. O delineamento experimental foi em blocos ao acaso com 4 repetições em arranjo fatorial 4x3, com 12 tratamentos, constituídos de 4 velocidades de deslocamento, obtidas em função dos escalonamentos de marchas e de 3 rotações do motor do trator. Durante a semeadura, monitorou-se a velocidade de operação, a rotação do motor e o deslizamento dos rodados motrizes da semeadora. Após a semeadura, foram avaliados: a profundidade de deposição de sementes, a distribuição longitudinal de sementes no leito de semeadura, o índice de velocidade de emergência e o tempo médio de emergência. Os resultados mostraram que, sob o aspecto qualitativo do processo de semeadura para a cultura do milho, é possível optar por menores velocidades de deslocamento em função do escalonamento de marcha e menores rotações no motor, ressaltando-se que as velocidades de 3,5 até $5,0 \mathrm{~km} \mathrm{~h}^{-1}$ proporcionaram os melhores resultados.

Palavras-chave: Emergência de plântulas, deslizamento da semeadora, profundidade da semente

\section{ABSTRACT \\ DISPLACEMENT SPEED AND THE GEAR SETTING OF A TRACTOR-SEEDER-FERTILIZER COMBINE AFFECTS QUALITY OF DIRECT MAIZE SOWING}

This study was done to evaluate the quality of the maize sowing by a tractor-seeder-fertilizer applicator combine in no-tillage system, using different displacement speeds and motor shaft rotations. The experiment was conducted in randomized block design with four replications in a 4 x 3 factorial. The treatments consisted of four forward speeds, adjusted by gear schedules and three motor shaft rotations of the tractor. Operational speed, engine speed and slippage of the wheeled planter were monitored during sowing. Seed deposit depth, longitudinal seed distribution, seedling emergence velocity and mean emergence time were evaluated. The qualitative aspect of the sowing process showed that it is possible to opt for lower displacement speeds by gear scheduling and lower engine rotations, with best results obtained at the speeds between 3.5 and $5,0 \mathrm{~km} \mathrm{~h}^{-1}$.

Keywords: seedling emergence, depth of seed, slippage seeder

Recebido para publicação em 23/08/2010. Aprovado em 07/02/2012.

1- Eng. Agrícola, Professor D.Sc. em Mecanização agrícola, Instituto Federal Goiano, campus Rio Verde - GO E-mail; jcmodernel@ yahoo.com.br

2- Eng. Agrícola, Professor Associado do Departamento de Engenharia Agrícola, Universidade Federal de Viçosa - UFV. E-mail: haroldo@ufv.br

3- Lic. em Ciências Agrícolas, Doutorando em Engenharia Agrícola, Universidade Federal de Viçosa - UFV. E-mail: daniel.mariano@ufv.br

4- Eng. Agrônomo, Professor Associado do Departamento de Engenharia Agrícola, Universidade Federal de Viçosa - UFV. E-mail: mauri@ufv.br

5- Eng. Agrônomo, Mestrando em Engenharia Agrícola, Universidade Federal de Viçosa - UFV. E-mail: marconi.junior@ufv.br 


\section{INTRODUÇ̃̃O}

O milho (Zea mays L.) é uma cultura cultivada em todo o território nacional, sendo ele utilizado tanto para a alimentação humana e ou animal, podendo, também, ser utilizado como na forma de combustível alternativo em alguns países.

$\mathrm{O}$ aumento da população mundial fez com que a agricultura abrisse novas fronteiras agrícolas, com intuito de aumentar a produção de grãos, com sementes de qualidade e certificadas. Contudo, não basta somente a certificação das sementes, mas também, solos estruturados, com temperatura e umidades adequadas, máquinas capazes de depositar o adubo e a semente a profundidades estabelecidas e velocidades de operações adequadas, para que o sucesso da produção seja pleno.

O plantio direto visa manter no solo uma cobertura vegetal, que provém de culturas anteriores, sendo fonte de matéria seca com diferentes relações carbono/nitrogênio $(\mathrm{C} / \mathrm{N})$. Apresenta como vantagem a redução nos custos operacionais de mecanização, levando-se em consideração os aspectos conservacionistas das propriedades físicas, químicas e biológicas do solo (NAGAOKA; NOMURA, 2003).

Os prejuízos advindos do uso irracional da maquinaria agrícola ao meio ambiente são conhecidos. Por isso, a tendência mundial está voltada para o uso de sistemas conservacionistas na agricultura mecanizada, como alternativa de minimizar os danos ao solo, à atmosfera, às plantas e ao próprio homem (FERNANDES et al., 2002).

De acordo com a EMBRAPA (1997), um dos parâmetros de grande influência na precisão de distribuição de sementes no solo é a velocidade da máquina. Em trabalho sobre a distribuição longitudinal de sementes em função do mecanismo dosador de sementes, Silveira et al. (2005) observaram dispersão elevada dos dados em todos os tratamentos, independentemente do tipo de semeadora utilizada e da velocidade de operação adotada, conforme Pimentel-Gomes (2002) e Garcia (2006). Esses altos valores de coeficiente de variação $(\mathrm{CV})$ indicaram que a distribuição das plantas no campo não é uniforme, e mesmo com a diminuição da velocidade ou a utilização de mecanismos mais sofisticados, como é o caso do sistema pneumático de distribuição de sementes, essa dispersão continuou elevada. Eles atribuíram os altos valores de $\mathrm{CV}$ à variação nas dimensões das sementes, altura e velocidade de queda no tubo de sementes, pois esses fatores tendem a desuniformizar a distribuição longitudinal das plantas.

A distribuição longitudinal de sementes na operação de semeadura, segundo Cortez et al. (2006), pode sofrer interferências com o escalonamento de marchas do trator, ocasionadas pela velocidade de operação do conjunto trator/ semeadora. Eles, ao avaliarem o espaçamento entre plantas com diferentes escalonamentos de marchas, concluíram que, na maior velocidade de operação, a quantidade de espaçamentos aceitáveis foi menor, o que resultou em aumento na quantidade de espaçamentos falhos. Resultados semelhantes foram encontrados por Garcia et al. (2006).

Pelo exposto, objetivou-se com este trabalho avaliar a qualidade da semeadura do milho em função do aumento da velocidade de deslocamento e do escalonamento de marcha de um conjunto trator-semeadora-adubadora.

\section{MATERIAL E MÉTODOS}

O experimento foi conduzido no Campo Experimental da Fundação Assis Gurgacz, em Cascavel, PR. A localização geográfica da área experimental está definida pelas coordenadas $24^{\circ} 56^{\prime} 30^{\prime \prime}$ de latitude sul e $53^{\circ} 30^{\prime} 28^{\prime \prime}$ de longitude oeste, com uma altitude média de $760 \mathrm{~m}$ e declividade entre 0 e $3 \%$. O delineamento experimental foi em blocos ao acaso, com quatro repetições, em arranjo fatorial $4 \times 3$, com 12 tratamentos, constituídos de quatro velocidades de deslocamento $(3,5 ; 4,0 ; 5,5 \mathrm{e}$ $7,0 \mathrm{~km} \mathrm{~h}^{-1}$ ), obtidas em função dos escalonamentos de marchas e de três rotações do motor do trator (1.500; 1.900 e $2.100 \mathrm{rpm})$, totalizando 48 unidades experimentais. Quando a interação entre os fatores velocidades de deslocamento e das rotações do motor foram significativa, utilizou-se a análise de regressão. Os modelos foram escolhidos com base na significância dos coeficientes de regressão, utilizandose o teste $\mathrm{t}$ a $5 \%$ de probabilidade e no coeficiente de determinação. Foi realizada a análise estatística dos dados utilizando o software SAEG 9.1 (UFV, 2007). 
Para tracionar a semeadora-adubadora, foi utilizado um trator marca FORD, modelo 7630 $4 \times 2$, com tração dianteira auxiliar(TDA), potência de $75,8 \mathrm{~kW}(103 \mathrm{cv})$ no motor a $2.100 \mathrm{rpm}$. Uma semeadora-adubadora marca Tatu Marchesan PST $^{3}$ de arrasto, com mecanismos dosadores de sementes do tipo disco perfurado horizontal, discos duplos para distribuição de sementes e sulcadores tipo haste (facão) para adubo.

Foram utilizadas sementes de milho híbrido AG 405 e fertilizante $\left(330 \mathrm{~kg} \mathrm{ha}^{-1}\right)$ na formulação NPK 8-20-20.

$\mathrm{Na}$ avaliação da qualidade da semeadura, foi avaliada:

- A profundidade de deposição de sementes de 25 plantas por linha, realizando a amostragem em quatro linhas de cada unidade experimental, a distribuição longitudinal das sementes, determinando os tipos de espaçamentos normais, duplos e falhos, segundo a metodologia proposta por Kurachi et al. (1989); e

- O índice de velocidade de emergência de plântulas (IVE) foi avaliado diariamente até que o número de plântulas emergidas se apresentasse constante. A partir dessas contagens, expressou-se o índice de velocidade de emergência de plântulas, utilizando-se a Equação 1, e o cálculo do tempo médio de emergência (TME), em dias, tendo como referência a Equação 2, descrita por Özmerzi et al. (2002).

IVE $=\sum_{i=1}^{n} \frac{N_{1}}{D_{1}}+\frac{N_{2}}{D_{2}}+\ldots \ldots+\frac{N_{n}}{D_{n}}$

em que

IVE = índice de velocidade de emergência;

$\mathrm{N}_{1}, \mathrm{~N}_{2}, \ldots, \mathrm{N}_{\mathrm{n}}=$ número de plantas emergidas, na primeira, segunda, ..., última contagem;

$\mathrm{D}_{1}, \mathrm{D}_{2}, \ldots, \mathrm{D}_{\mathrm{n}}=$ número de dias da semeadura à primeira, segunda, ..., última contagem.

$T_{m}=\frac{N_{1} T_{1}+N_{2} T_{2}+\ldots+N_{n} T_{n}}{N_{1}+N_{2}+\ldots+N_{n}}$ em que

$\mathrm{T}_{\mathrm{m}}=$ tempo médio de emergência (dias);

$\mathrm{N}_{1 \ldots \mathrm{n}}=$ número de sementes emergidas desde a primeira contagem; e

$\mathrm{T}_{1 \ldots \mathrm{n}}=$ número de dias após a semeadura.

O deslizamento da roda motriz da semeadoraadubadora foi determinada utilizando-se dois sensores indutivos, modelo IB-5M-18CA-NA/XL acoplados a uma engrenagem motriz. Pela relação entre o número de voltas da roda acionadora de distribuição de sementes, foi determinada o deslizamento ao longo de todo o comprimento da unidade experimental.

\section{RESULTADOS E DISCUSSÃO}

$\mathrm{O}$ valor médio da biomassa na área experimental foi de 2,41 t ha ${ }^{-1}$. A quantidade de biomassa é importante para a manutenção da umidade do solo e proteção física do solo, além de disponibilizar nutrientes para culturas posteriores, como também suprimir plantas invasoras. Os teores médios de água e de massa específica no solo na profundidade de $0-0,10 \mathrm{~m}$, foram de $0,32 \mathrm{~kg} \mathrm{~kg}^{-1}$ e $1,05 \mathrm{Mg} \mathrm{m}^{-3}$, respectivamente, e na profundidade de $0,10-0,20 \mathrm{~m}$, os valores médios foram de $0,26 \mathrm{~kg} \mathrm{~kg}^{-1} \mathrm{e} 1,11 \mathrm{Mg} \mathrm{m}^{-3}$. O maior valor encontrado para a resistência mecânica do solo à penetração (MPa) na área experimental foi de 1,36 MPa na profundidade de $0-0,10 \mathrm{~m}$.

A velocidade de deslocamento do conjunto apresentou diferenças significativas para todos os parâmetros avaliados, sendo observadas diferenças significativas para a interação entre as fontes de variação (velocidade de deslocamento versus rotação do motor) para os parâmetros índice de velocidade emergência e tempo médio de emergência de plântulas, podendo ser observado nas sínteses das análises de variância apresentadas nas Tabelas 1 e 2. Observouse também, para os espaçamentos aceitáveis, falhos, índice de velocidade de deslocamento e tempo médio de emergência de plântulas, diferença significativa quando se variou a rotação do motor. Com esses resultados, optou-se em realizar análises de regressões para verificar entre as fontes de variação qual o de maior influência nas variáveis em estudos. Observou- 
se então, a velocidade de deslocamento como o fator de maior importância. Neste intuito, foram realizadas análises de regressões para os parâmetros avaliados, e os modelos escolhidos de acordo com a significância dos CV, utilizando-se o teste de t a 5\% de probabilidade, e no coeficiente de determinação.

O modelo encontrado e ajustado através da análise de regressão para a profundidade de deposição das sementes é apresentado na Figura 1.

A semeadora-adubadora foi regulada para depositar as sementes a uma profundidade de $0,05 \mathrm{~m}$. Entretanto, ela variou de 0,046 a $0,053 \mathrm{~m}$, da maior para a menor velocidade de operação.

$O$ aumento na velocidade de operação acarretou a colocação das sementes no solo mais superficialmente, evitando maior contato com este e impedindo que elas venham a germinar e desenvolver, provavelmente pela diminuição da absorção de água, como pode ser verificado na equação de regressão apresentada na Figura 1. Esse resultado está relacionado com os mecanismos de controle de profundidade da semeadora-adubadora, um problema que vem sendo observado e discutido por vários autores (ANDREOLI et al., 2002; COSTA et al., 2002; MAHL et al., 2004; e, SILVEIRA et al., 2005). Contudo, Furlani et al. (1999) observaram que a profundidade de deposição de semente não foi afetada pelo aumento da velocidade de deslocamento. Mesmo com pequena variação na profundidade de deposição da semente, pode-se afirmar que a semeadora-adubadora desempenhou qualidade satisfatória na profundidade de deposição das sementes.

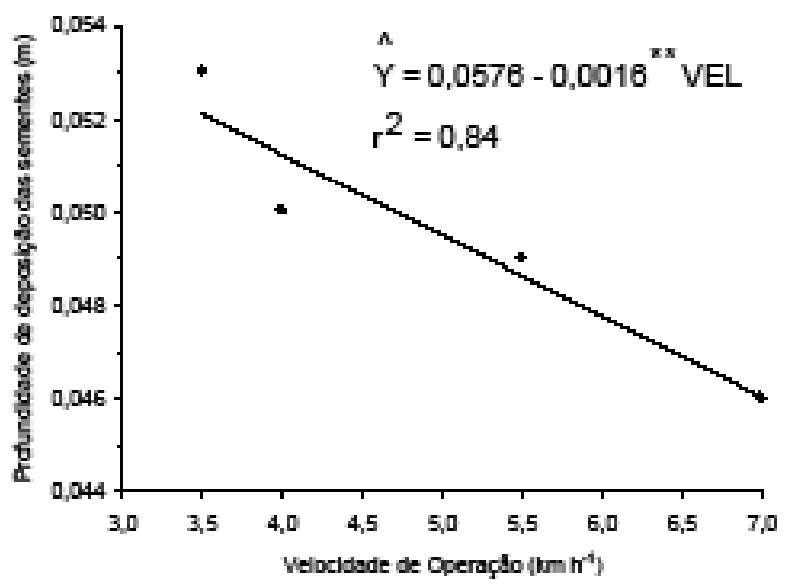

Figura 1. Estimativa da profundidade de deposição da semente em função da velocidade de operação do conjunto mecanizado.

Quadro 1. Síntese da análise de variância para os parâmetros: Espaçamentos Aceitáveis (EA), Espaçamentos Múltiplos (EM), Espaçamentos Falhos (EF) e Variação da Distribuição (VD)

\begin{tabular}{ccccc}
\hline Fator & EA & EM & EF & VD \\
\hline Velocidade (V) & $236,62^{* *}$ & $3,39^{*}$ & $136,14^{* *}$ & $18,87^{* *}$ \\
Rotações (R) & $6,58^{* *}$ & $0,63^{\text {ns }}$ & $3,87^{*}$ & $1,85^{\text {ns }}$ \\
R x V & $1,57^{\text {ns }}$ & $0,52^{\text {ns }}$ & $0,97^{\text {ns }}$ & $0,86^{\text {ns }}$ \\
\hline CV (\%) & 4,50 & 76,32 & 16,94 & 20,41 \\
\hline
\end{tabular}

*- Significativo a 5\%, pelo teste de Tukey,

** - Significativo a $1 \%$, pelo teste de Tukey,

ns - Não significativo

Quadro 2. Síntese da análise de variância para os parâmetros: Profundidade de Semeadura (PS), Deslizamento do Rodado Motriz da Semeadora (PRM), Índice de Velocidade de Emergência (IVE) e Tempo Médio de Emergência (TME)

\begin{tabular}{ccccc}
\hline Fator & PS & PRM & IVE & TME \\
\hline Velocidade (V) & $15,93^{* *}$ & $43,72^{* *}$ & $11,90^{* *}$ & $44,55^{* *}$ \\
Rotações (R) & $0,88^{\text {ns }}$ & $0,11^{\text {ns }}$ & $17,66^{* *}$ & $12,56^{\text {ns }}$ \\
R x V & $0,46^{\text {ns }}$ & $1,42^{\text {ns }}$ & $4,83^{* *}$ & $3,68^{* *}$ \\
\hline C.V (\%) & 4,98 & 55,89 & 8,73 & 4,02 \\
\hline
\end{tabular}

* - Significativo a 5\%, pelo teste de Tukey,

** - Significativo a 1\%, pelo teste de Tukey,

ns - Não significativo 
O deslizamento dos rodados da semeadoraadubadora não apresentou diferença significativa para as fontes de variação, e a mesma ficou abaixo dos padrões estabelecidos por Balastreire (2005) e pela ASAE (1996). Neste trabalho, o valor do deslizamento foi abaixo dos $3 \%$.

De acordo com a regulagem da semeadoraadubadora, determinou-se o espaçamento de referência teórico de $0,17 \mathrm{~m}$. Esse valor possibilitou que fossem classificados como espaçamentos aceitáveis $(0,09<\mathrm{xi}<0,26)$, múltiplos $(\mathrm{xi}<0,09)$ e falhos ( $x i>0,26)$.

O modelo ajustado para o espaçamento aceitável entre sementes apresentou comportamento linear decrescente com o aumento da velocidade de operação (Figura 2). Ou seja, a cada unidade acrescida na velocidade os espaçamentos aceitáveis entre sementes decresceram em 8,94\%. O índice de determinação $\left(r^{2}=0,95\right)$ possibilita afirmar a forte influência da velocidade de operação na variável em estudo.

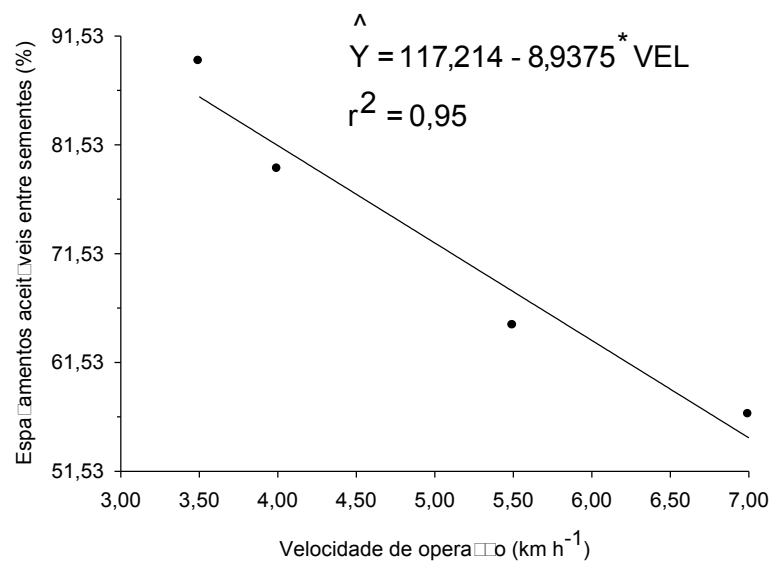

Figura 2. Estimativa do espaçamento aceitável entre sementes em função da velocidade de operação do conjunto mecanizado.

O maior valor porcentual de espaçamentos aceitáveis foi obtido na menor velocidade $\left(3,5 \mathrm{~km} \mathrm{~h}^{-1}\right)$, decrescendo com o aumento da mesma. Esses resultados corroboram com os encontrados por Branquinho et al. (2004) e Garcia et al. (2006). Contudo, abaixo dos encontrados por Jasper et al. (2006) e, acima dos estipulados por Coelho (1996), que considera para semeadoras dotadas de mecanismos do tipo disco horizontal, um espaçamento aceitável de
$60 \%$. À exceção da velocidade de operação de $7,0 \mathrm{~km} \mathrm{~h}^{-1}$, em que se obtiveram percentuais abaixo do estipulado (60\%). Mantovani et al. (1992), ao avaliarem nove semeadoras-adubadoras de plantio direto, encontraram valores entre $44 \mathrm{e}$ $78 \%$ de espaçamentos aceitáveis em diferentes velocidades de deslocamentos. Analisando os resultados percebeu-se que a semeadoraadubadora alcançou bom desempenho nas menores velocidades $\left(3,5\right.$ e 4,0 $\left.\mathrm{km} \mathrm{h}^{-1}\right)$ e regular em 5,5 e $7,0 \mathrm{~km} \mathrm{~h}^{-1}$, conforme parâmetros determinados por Tourino e Klingensteiner, (1983).

A equação de regressão dos espaçamentos múltiplos entre sementes é apresentada na Figura 3. Pelo modelo ajustado e observado na equação, verifica-se que, a cada incremento na velocidade de operação do conjunto mecanizado, ocorre aumento no espaçamento múltiplo de semente de $1,13 \%$, sendo maiores nas maiores velocidades de deslocamentos $\left(5,5\right.$ e 7,0 $\left.\mathrm{km} \mathrm{h}^{-1}\right)$. Os valores médios dos espaçamentos múltiplos de sementes nas velocidades de 3,5 e $5,0 \mathrm{~km} \mathrm{~h}^{-1}$ estão abaixo dos encontrados por Camilo et al. (2004).

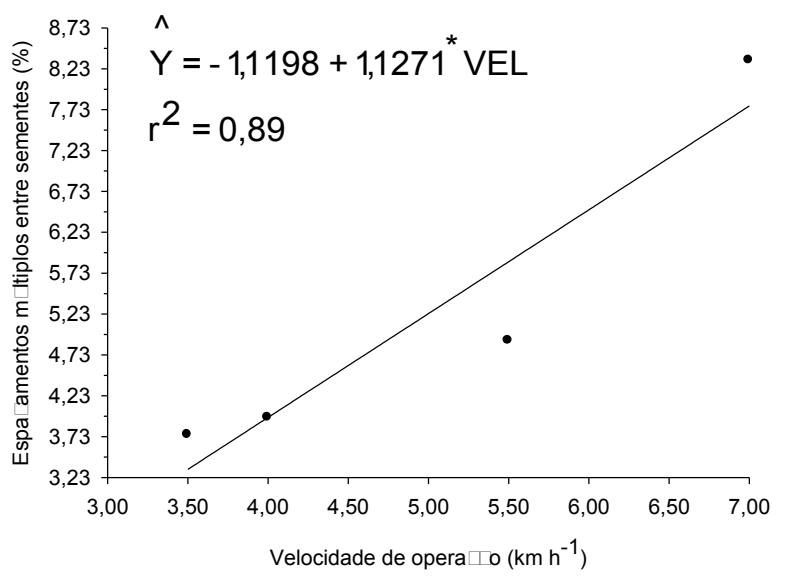

Figura 3. Estimativa dos espaçamentos múltiplos de sementes em função da velocidade de operação do conjunto mecanizado.

Na Figura 4, mostra-se o gráfico de regressão linear e a equação de regressão do modelo ajustado para espaçamento falho entre sementes. Observase para os dados de espaçamentos falhos entre sementes, comportamento linear crescente, com coeficiente de determinação $\left(\mathrm{r}^{2}\right)$ de 0,91 , com forte relação com a variável estudada (espaçamentos falhos). A cada aumento na velocidade de operação 
do conjunto mecanizado, os espaçamentos falhos tiveram incremento na ordem de 7,67\%. É evidenciado que o aumento na velocidade de operação do conjunto mecanizado influi na diminuição dos espaçamentos aceitáveis e no aumento do número de espaçamentos falhos, contribuindo para o insucesso do estande de plantas no campo e para a produção.

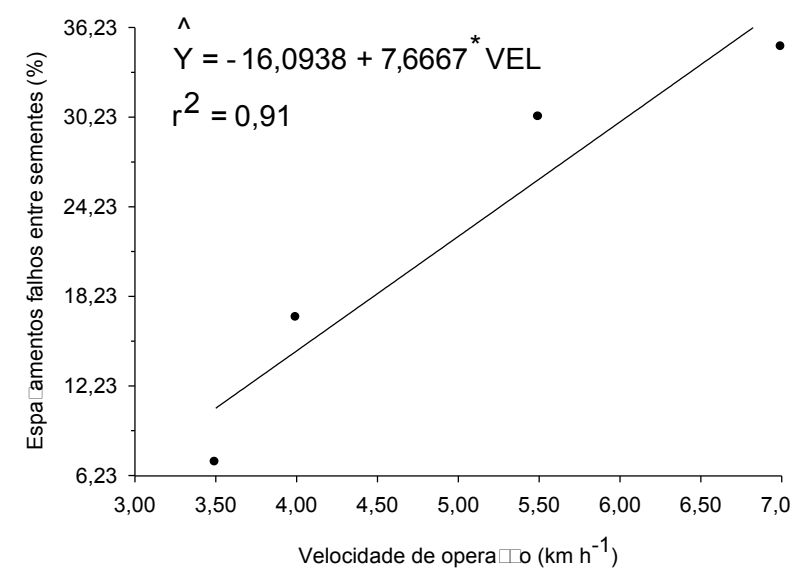

Figura 4. Estimativa dos espaçamentos falhos de sementes em função da velocidade de operação do conjunto mecanizado.

$\mathrm{Na}$ Figura 5, apresenta-se o gráfico da estimativa do coeficiente de variação da distribuição longitudinal de sementes no leito de semeadura em função da velocidade de operação, bem como a equação do modelo proposto pela análise de regressão e escolhido pelo coeficiente de determinação $\left(r^{2}\right)$. Verifica-se nessa equação que, a cada unidade de variação na velocidade de operação do conjunto mecanizado, o coeficiente de variação da distribuição longitudinal de sementes aumenta em 7,35\%. O coeficiente de variação da distribuição longitudinal de sementes deve ficar abaixo de 50\% (COELHO, 1996), não sendo observado nas velocidades de 5,5 e 7,0 $\mathrm{km} \mathrm{h}^{-1}$, em que se verificou maior variabilidade dos dados, demonstrando nessas velocidades que a distribuição não foi uniforme.

Resultados semelhantes foram observados por Silveira et al. (2005) quando avaliaram tipos de mecanismos dosadores de sementes em função da velocidade de operação de duas semeadorasadubadoras, e diferentes dos obtidos por Mahl et al. (2004) quando avaliaram a eficiência de distribuição de sementes em diferentes velocidades de deslocamento. Pode-se definir como velocidades ideais de operação para a semeadura, sem causar variações na distribuição de sementes às velocidades de 3,5 a 4,0 $\mathrm{km} \mathrm{h}^{-1}$. Entretanto, Silveira (1989) definiu a velocidade de 5,0 $\mathrm{km} \mathrm{h}^{-1}$ como a ideal. Já Klein et al. (2002) definiram como ideais as velocidades entre 3,6 a $10,8 \mathrm{~km} \mathrm{~h}^{-1}$ com o mesmo mecanismo dosador.

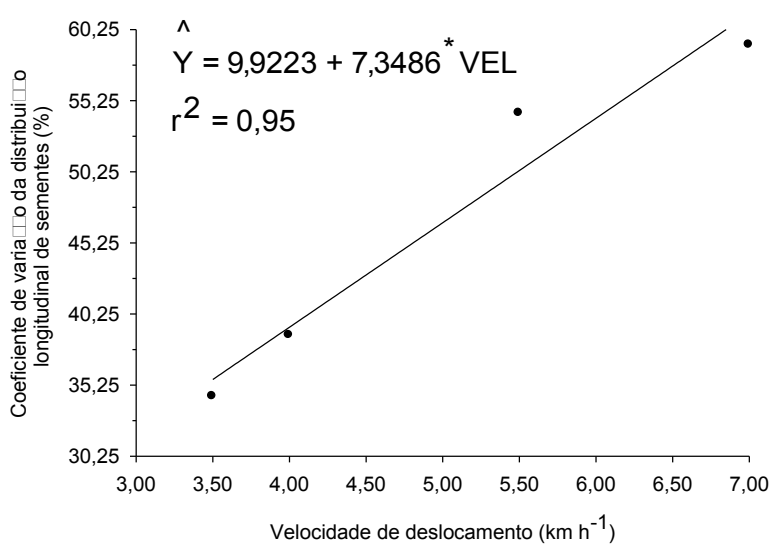

Figura 5. Estimativa do coeficiente de variação para a distribuição longitudinal de sementes em função da velocidade de operação do conjunto mecanizado.

Na Figura 6, têm-se a equação de regressão e o gráfico da estimativa do índice de velocidade de emergência das plântulas. O IVE apresentou modelo de regressão linear decrescente com o aumento da velocidade de operação, ou seja, a cada incremento na velocidade ocorre um decréscimo de 4,57 no IVE, o que corresponde a $41 \%$ da maior para a menor velocidade de operação. Portella et al. (1997) e Faganello et al. (1999) não observaram diminuição no índice de emergência com o aumento da velocidade de operação. Os maiores índices foram verificados nas menores velocidades de deslocamento (3,5 e 4,0 $\left.\mathrm{km} \mathrm{h}^{-1}\right)$. Silveira (2005) encontrou resultados opostos aos desta pesquisa.

A equação de regressão do modelo ajustado, bem como o gráfico de regressão para o tempo médio de emergência de plântulas é apresentado na Figura 7. A cada incremento na velocidade de operação ocorre um aumento de 0,26 dias no TME. Essa diferença pode ser atribuída à posição da semente ao ser depositada no solo pelos mecanismos de deposição, o que pode também ocasionar a falta de 
contato entre as sementes e o solo.

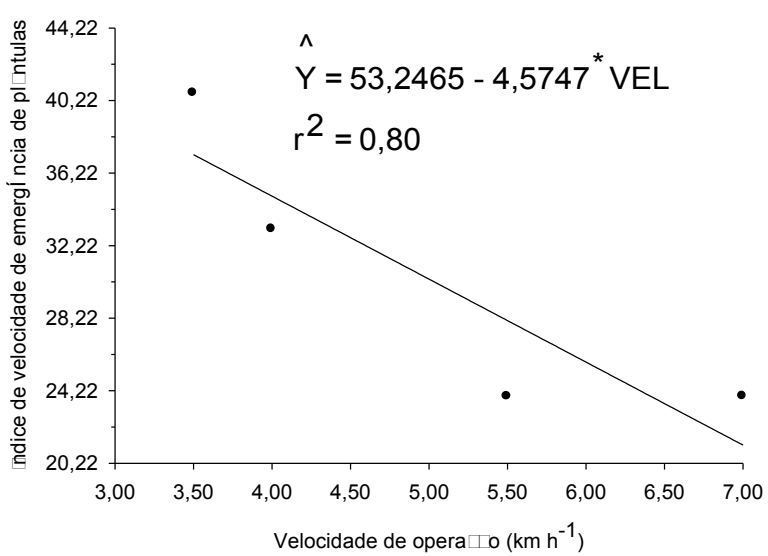

Figura 6. Estimativa do índice de velocidade de emergência de plântulas de milho em função da velocidade de operação do conjunto mecanizado.

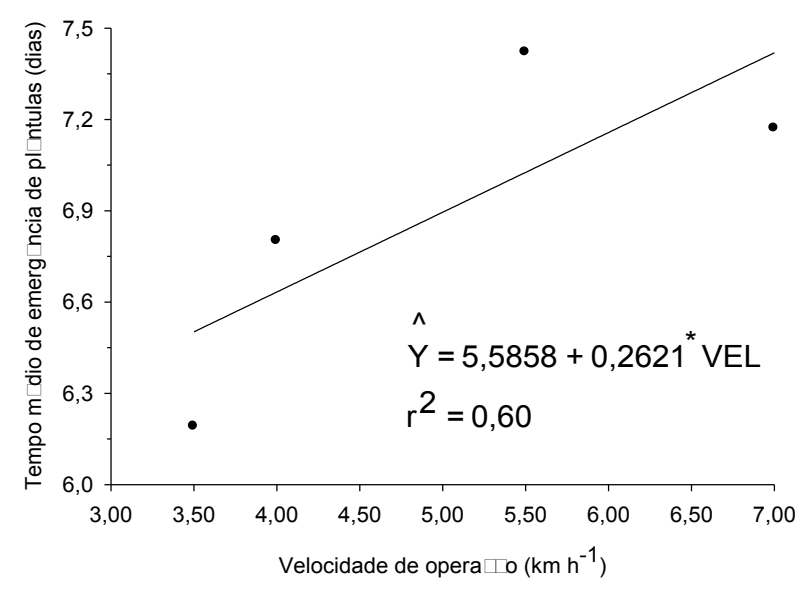

Figura 7. Estimativa do tempo médio de emergência de plântulas de milho (dias) em função da velocidade de operação do conjunto mecanizado.

\section{CONCLUSÃO}

Nas condições em que foi realizado esse trabalho, pode-se concluir que:

- as diferentes rotações utilizadas não interferem nos parâmetros de qualidade da semeadura;

- o aumento da velocidade de operação do conjunto mecanizado foi o fator de maior influência sobre os parâmetros de qualidade da semeadura, principalmente quando nas maiores velocidades de operação;

- o deslizamento das rodas motrizes da semeadora-adubadora não teve influência negativa para a distribuição de sementes no leito de semeadura;

- para essa conformação do conjunto trator semeadora-adubadora, e nas velocidades ensaiadas é possível tecnicamente aumentar a qualidade de semeadura alternando o escalonamento de marcha em função da rotação do motor; e

- os resultados mostram-se satisfatórios para as velocidades entre 3,5 a $4,0 \mathrm{~km} \mathrm{~h}^{-1}$ e regulares para a velocidade de operação de $5,0 \mathrm{~km} \mathrm{~h}^{-1}$.

\section{REFERÊNCIAS BIBLIOGRÁFICAS}

AMERICAN SOCIETY OF AGRICULTURAL ENGINEERS. Agricultural machinery management data. In:_ ASAEstandards 1996. St. Joseph, Michigan, 1996. p. 332-339. (ASAE S313.2).

ANDREOLI, C.; ANDRADE, R.V.; ZAMORA, S.A.; GORDON, M. Qualidade da semente e densidade de semeadura no estabelecimento $\mathrm{e}$ na produtividade do milho. Sete Lagoas, MG: Embrapa Milho e Sorgo, 2002. 15p. (Boletim de pesquisa e desenvolvimento 1, dez. 2002. EMBRAPA-MG).

BALASTREIRE, L.A. Máquinas agrícolas. 1. ed. São Paulo: Manole, 2005. 307p.

BRANQUINHO,K.B.;FURLANI,C.E.A.;LOPES, A.; SILVA, R.P.; GROTTA, D.C.C.; BORSATTO, E.A. Desempenho de uma semeadora-adubadora direta, em função da velocidade de operação do tipo de manejo da biomassa da cultura de cobertura do solo. Revista Engenharia Agrícola, Jaboticabal, v.24, n.2, p.374-380, 2004.

CAMILO, J.A.; FERNANDES, H.C.; MODOLO, A.J.; RESENDE, R.C. Influência de mecanismos rompedores e velocidades de trabalho no desempenho de uma semeadoraadubadora de plantio direto do feijão. Engenharia na Agricultura, Viçosa, v.12, n.3, p.203-211, 2004. 
COELHO, J.L.D. Ensaio e certificação das máquinas para a semeadura. In: MIALHE, L.G. Máquinas agrícolas: ensaios e certificação. Piracicaba, SP: Fundação de Estudos Agrários Luiz de Queiroz, 1996. p.551-70.

CORTEZ, J.W.; FURLANI, C.E.A.; SILVA, R.P.; LOPES, A. Distribuição longitudinal de sementes de soja e características físicas do solo no plantio direto. Revista Engenharia Agrícola, Jaboticabal, v.26, n.2, p.502-510, 2006.

COSTA, M.; STIPP, O.J.; MODOLO, A.J.; SILVA, S.L.; GABRIEL FILHO, A. Força de tração requerida por uma semeadora-adubadora em diferentes profundidades de deposição de sementes de milho. In: CONGRESSO BRASILEIRO DE ENGENHARIA AGRÍCOLA, 31. Salvador, BA, 2002. Anais... Salvador: Sociedade Brasileira de Engenharia Agrícola, 2002, CD-Rom.

EMPRESA BRASILEIRA DE PESQUISA AGROPECUÁRIA. Recomendações técnicas para o cultivo do milho. 2.ed. Brasília; 1997. 204p.

FAGANELlO, A.; SATTLER, A.; PORTELLA, J.A. Eficiência de semeadoras na emergência de plântulas de milho (Zea mays $L$.) sob sistema plantio direto. Passo Fundo, RS: Embrapa Trigo, 1999.

FERNANDES,H.C.;OLIVEIRA,A.D.; PANEQUE, P.R. Comparação de diferentes sistemas de preparo do solo e semeadura com relação ao consumo de energia. In: CONGRESSO BRASILEIRO DE ENGENHARIA AGRÍCOLA, 31, 2002, Salvador, BA. Anais... Salvador: Sociedade Brasileira de Engenharia Agrícola, 2002. CD-Rom.

FURLANI, C.E.A.; LOPES, A.; ABRAHÃO, F.Z.; LEITE, M.A.S. Características da cultura do milho (Zea mays L.) em função do tipo de preparo do solo e da velocidade de semeadura. Revista Engenharia Agrícola, Jaboticabal, v.19, n.2, p.177-186, 1999.

GARCIA, L.C.; JASPER, R.; JASPER, M.; FORNARI, A.J.; BLUM, J. Influência da velocidade de operação na semeadura do milho. Revista Engenharia Agrícola, Jaboticabal, v. 26, n. 2, p. 520-527, 2006.
JASPER, R.; JANSZEN, U.; JASPER, M.; GARCIA, L. Distribuição longitudinal e germinação de sementes de milho com emprego de tratamento fitossanitário e grafite. Revista Engenharia Agrícola, Jaboticabal, v.26, n.1, p.292-299, 2006.

KLEIN. V.A.; SIOTA, T. A.; ANESI, A.L.; BARBOSA, R. Efeito da velocidade na semeadura direta da soja. Revista Engenharia Agrícola, Jaboticabal, v. 22, n.1, p.75-82, 2002.

KURACHI, S.A.H.; COSTA, J.A.S.; BERNARDI, J.A.; COELHO, J.L.O.; SILVEIRA, G.M.Avaliação tecnológica de semeadoras e/ou adubadoras, tratamento de dados de ensaios e regularidade de distribuição longitudinal de sementes. Bragantia, v.48, n.2, p.249-62, 1989.

MAHL, D.; GAMERO, C.A.; BENEZ, S.H.; FURLANI, C.E.A.; SILVA, A.R.B. Demanda energética e eficiência da distribuição de sementes de Milho sob variação de velocidade e condição de solo. Revista Engenharia Agrícola, Jaboticabal, v.24, n.1, p.150-157, 2004.

MANTOVANI, E.C.; BERTAUX, S.; ROCHA, F.E.C. Avaliação da eficiência operacional de diferentes semeadoras-adubadoras de milho. Pesquisa Agropecuária Brasileira, v.27., p.157986, 1992.

NAGAOKA, A.K.; NOMURA, R.H.C. Tratores: semeadura. Cultivar Máquinas, Pelotas, n.18, p.246, 2003.

ÖZMERZI, A.; KARAYEL, D.; TOPAKEI, M. Effect of sowing depth on precision seeder uniformity. Biosystems Engineering, v. 82, n. 2, p.227-230, 2002.

PIMENTEL-GOMES, F.; GARCIA, C.H. Estatística aplicada a experimentos agronômicos e florestais: Exposição com exemplos e orientações para uso de aplicativo. Piracicaba, SP: Fealq., 2002.

PORTELLA,J.A.;SATTLER,A.;FAGANELLO, 
A. Regularidade de distribuição de sementes e de fertilizantes em semeadoras para Plantio Direto. In: CONGRESSO BRASILEIRO DE ENGENHARIA AGRÍCOLA, 26., 1997, Campina Grande, PB. Anais... Campina Grande: Sociedade Brasileira de Engenharia Agrícola, CD-Rom.

SILVEIRA, G.M. As máquinas para plantar. Rio de Janeiro: Globo, 1989. 257p.

SAEG Sistema para análises Estatísticas, Versão 9.1: Fundação Arthur Bernardes - UFV, Viçosa, 2007.
SILVEIRA, J.C.M.; MODOLO, A.J.; SILVA, S.L.; GABRIEL FILHO, A. Força de tração e potência em duas velocidades de deslocamento e duas profundidades de deposição de sementes. Revista Engenharia Agrícola e Ambiental, Campina Grande, v.9, n.1, p.125-128, 2005.

TOURINO, M.C.; KLINGENSTEINER, P. Ensaio e avaliação de semeadoras-adubadoras. In: CONGRESSO BRASILEIRO DE ENGENHARIA AGRÍCOLA, 13., 1983, Rio de Janeiro, RJ. Anais... Rio de Janeiro: UFRRJ, 1983. v.2, p.103-116. 